\title{
Analysis of Skills Sought by Employers of Bachelors-Level Geoscientists
}

Gregory Shafer, Karen Viskupic, Dept. of Geosciences, Boise State University, Boise, Idaho 83725, USA; Anne E. Egger, Dept. of

Geological Sciences, Central Washington University, Ellensburg, Washington 98926, USA

\section{INTRODUCTION}

Bachelors-level geoscientists make up the majority of the geoscience workforce, and positions for entry-level geoscientists are expected to grow rapidly over the next decade, with some jobs anticipating upward of $10 \%$ growth (National Center for O*NET Development, 2021). Are geoscience departments adequately preparing undergraduate students to succeed in these positions?

Answering this question requires examining the alignment of undergraduate program outcomes and workforce needs. The results allow faculty to identify strengths and weaknesses in their programs with respect to workforce preparation (e.g., Viskupic et al., 2020). How well do we know workforce needs? Vision and Change in the Geosciences (Mosher and Keane, 2021) provides a list of competencies and skills necessary for new graduates to succeed in the workforce; the list was generated by academics $(n \sim 200)$ and employers $(n=46)$ in a series of workshops. This list, while comprehensive and insightful, represents input from a relatively small sample of geoscience employers and may overrepresent the petroleum industry ( $26 \%$ of industry workshop participants), which has not been a significant employer of bachelorslevel geoscientists (Gonzales and Keane, 2021). Our goal was to characterize the skills sought by the full range of bachelorslevel geoscience employers and how these skills are communicated to potential applicants - with an eye toward providing information that would allow academic leaders to examine the alignment between their programs and workforce needs.

\section{WHAT WE DID}

We designed a systematic study to code online geoscience job advertisements (hereafter referred to as "ads") for workforce skills. Ads were retrieved between May and
November 2020 from four online job search engines: CareerBuilder.com; USAJobs.gov; CollegeRecruiter.com; Indeed.com. We limited our analysis to ads that preferred a bachelor's degree in geoscience or a related field and required less than five years of experience. A total of 1,214 unique ads met these criteria. Occupation names and industry sectors, described in AGI's 2018 Status of the Geoscience Workforce report (Wilson, 2018), were assigned to each ad based on job title and description of duties. The most common occupations in our sample were geologist, environmental scientist, and natural resource specialist, following a distribution similar to the AGI report (Table 1).

Ads were coded for 34 skills; many were listed by Mosher and Keane (2021) and others emerged through multiple rounds of coding ad subsamples. We defined the skills and organized them into categories (e.g., data skills, communication skills) according to the classification of Viskupic et al.

\section{TABLE 1. PERCENT OCCUPATIONAL DISTRIBUTION BY INDUSTRY SECTOR}

\begin{tabular}{lcc}
\hline \hline Industry sector & $\begin{array}{c}\text { Study sample } \\
(\%)\end{array}$ & $\begin{array}{c}2018 \text { AGI data } \\
(\%)\end{array}$ \\
\hline Professional, scientific, and technical services & 39.0 & 35.9 \\
Federal government & 15.9 & 10.2 \\
State government & 9.4 & 14.2 \\
Construction & 6.6 & 0.2 \\
Waste management and remediation services & 4.5 & 1.5 \\
Information services & 4.0 & 0.0 \\
Mining & 3.8 & 0.7 \\
Local government & 3.6 & 8.7 \\
Testing laboratories & 2.0 & N.D. \\
Utilities & 1.9 & 1.5 \\
Computer systems and design & 1.8 & N.D. \\
Manufacturing & 1.7 & 3.6 \\
Education* & 1.5 & 13.4 \\
Oil and gas & 1.5 & 7.6 \\
Scientific research and development & 1.2 & N.D. \\
Finance and insurance & 0.7 & 0.0
\end{tabular}

N.D. = no data

*Jobs in $\mathrm{K}-12$ education are largely not advertised using the search engines included in this study and thus are underrepresented in our data compared to the AGI data.

GSA Today, v. 32, https://doi.org/10.1130/GSATG510GW.1. CC-BY-NC. 


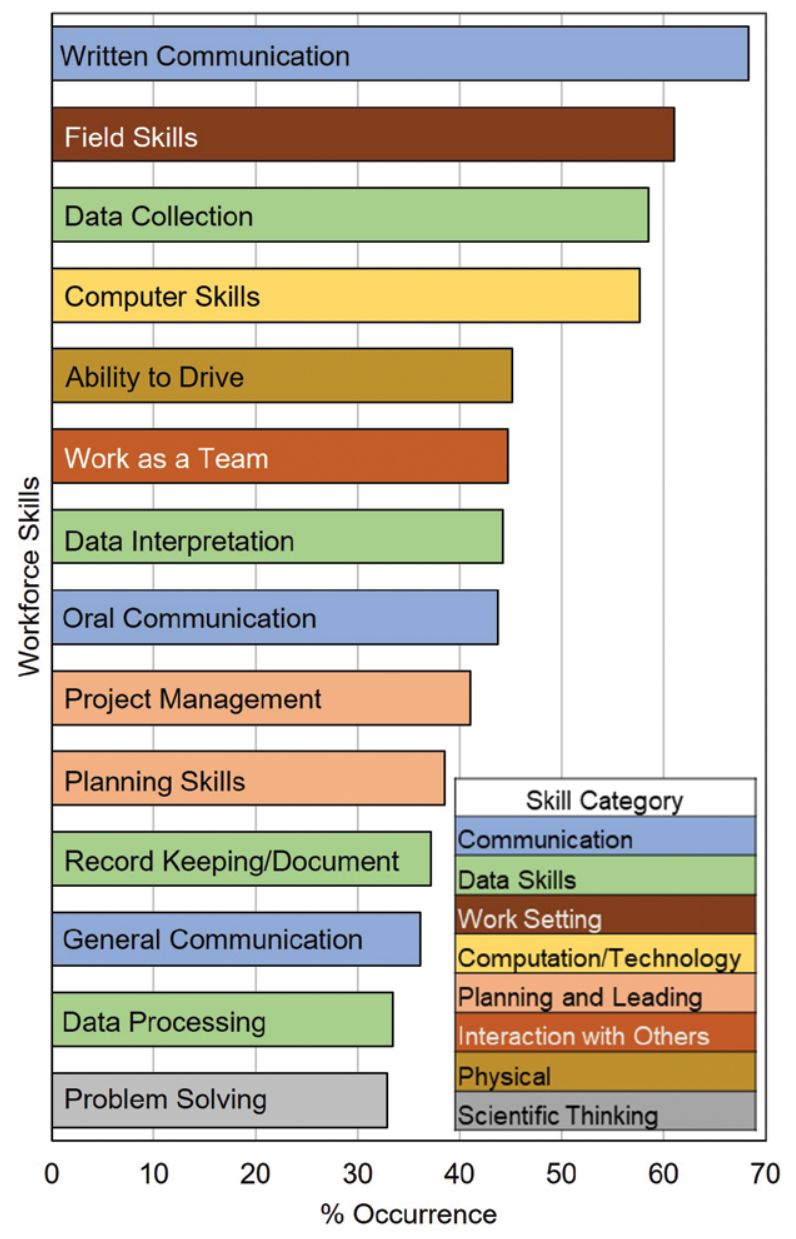

The most common skills varied greatly among employment sectors. For example, teamwork skills were found in $60 \%$ of mining ads but only $22 \%$ of oil and gas ads.

\section{HOW CAN OUR WORK BE USED?}

Our results provide geoscience departments with current representation of the most sought-after workforce skills that bachelors-level graduates need to be successful in the current job market. Proficiency in the whole spectrum of data skills - from data collection and record keeping to interpretation-is critical; these skills are practiced across many geoscience courses (Viskupic et al., 2020) and can be highlighted as workforce skills. We also note the emphasis on communication skills, leadership, project management, and planning. None of these skills are content-specific and may be less commonly explicit in curricula. Written communication skills are more commonly practiced in geoscience courses than oral or other?
Figure 1. The most common skills by percent occurrence from the job advertisement analysis. Skills are colored to correspond to skill categories outlined in Viskupic et al. (2020). graduates: Do advertisements that require physical abilities present unnecessary barriers to applicants with disabilities?

5. The articulation of systems thinking in job ads: Systems thinking is emphasized in Vision and Change in the Geosciences but was not found in any ads. How do employers articulate systems thinking skills in job ads?

6. Dispositions sought by employers: Dispositions (e.g., attention to detail, taking initiative) were distinct from skills, and appeared in many job ads. Which dispositions are most frequently sought, and to what extent can these be developed as part of geoscience programs?

\section{SUMMARY}

Our analysis of job advertisements presents a comprehensive view of the workforce skills sought by geoscience employers. Geoscience departments can use these results to inform their curriculum planning and incorporate opportunities for students to practice and develop competencies. The work presented here is a critical step in ensuring that the geoscience community is adequately preparing new graduates to succeed in the workforce.

\section{REFERENCES CITED}

Gonzales, L., and Keane, C., 2021, Recent Geoscience Graduate Employment Trends, December 2020: Washington, D.C., American Geosciences Institute, 4 p., https://www.americangeosciences.org/ geoscience-currents/recent-geoscience-graduate -employment-trends-december-2020 (last accessed 18 Mar. 2021).

Mosher, S., and Keane, C., 2021, Vision and Change in the Geosciences: The Future of Undergraduate Geoscience Education: Washington, D.C., American Geosciences Institute, 176 p.

National Center for O*NET Development, 2021, O*NET OnLine: https://www.onetonline.org/ (accessed March 2021).

Viskupic, K., Egger, A.E., McFadden, R.R., and Schmitz, M.D., 2020, Comparing desired workforce skills and reported teaching practices to model students' experiences in undergraduate geoscience programs: Journal of Geoscience Education, p. 27-42, https://doi.org/10.1080/108 99995.2020.1779568.

Wilson, C., 2018, Status of the geoscience workforce: Washington, D.C., American Geosciences Institute, $178 \mathrm{p}$.

logic mapping, installing, and monitoring field instrumentation, collecting samples,

4. The presence of physical abilities in job ads and their potential impact on recent
Manuscript ReCeived 11 Apr. 2021

REVISED MANUSCRIPT RECEIVED 21 OCT. 2021 ManusCript ACCePted 27 OCt. 2021 